\title{
Understanding the role of values in institutional change: the case of the energy transition
}

\author{
Christine Milchram $^{1 *} \mathbb{D}$, Carolin Märker ${ }^{2}$, Holger Schlör $^{2}$, Rolf Künneke ${ }^{1}$ and Geerten van de Kaa ${ }^{1}$
}

\begin{abstract}
The current transition towards low-carbon energy systems does not only involve changes in technologies but is also shaped by changes in the rules and regulations (i.e., the institutions) that govern energy systems. Institutional change can be influenced by changes in core values-normative principles such as affordability, security of supply, and sustainability. Analyzing this influence, however, has been hindered by the absence of a structured framework that highlights the role of values in institutional change processes. This paper presents an interdisciplinary framework explicating how values influence institutional change in the case of the energy transition. We build on a dynamic framework for institutional change that combines the Institutional Analysis and Development (IAD) framework with the concept of social learning. This basic analytical framework is expanded by conceptualizations of values in moral philosophy, institutional economics, and social psychology. Our framework offers researchers and policy makers an analytical tool to identify how values are embedded in infrastructure and existing regulation and how values shape communities and behavior. It explains how value controversies can trigger social learning processes that eventually can result in structural change. Thus, this framework allows analyzing institutional change over time as well as comparing change patterns across spatial and temporal contexts.
\end{abstract}

Keywords: Institutional analysis, Values, IAD framework, Social learning, Energy policy, Energy transition

\section{Background}

Energy systems are currently undergoing profound transition processes towards low-carbon systems. This transition does not only include changes to energy technologies or infrastructures. It is also shaped by changes in the institutions (the "rules of the game", e.g., legislation and regulation) that govern energy systems. Most aspects of generation, distribution, and consumption of energy are subject to regulation $[1,2]$. The Institutional Analysis and Development (IAD) framework developed by Elinor Ostrom and her colleagues $[3,4]$ is widely used by social scientists and policy analysts to understand institutions in various sectors, including energy systems $[1,5-7]$. A dynamic version of the original IAD framework is used in this paper to capture institutional change [8]. However,

\footnotetext{
* Correspondence: c.milchram@tudelft.nl

${ }^{1}$ Faculty of Technology, Policy and Management, Delft University of

Technology, Jaffalaan 5, 2628 BX Delft, Netherlands

Full list of author information is available at the end of the article
}

this framework is limited in recognizing important drivers of institutional change: values and value changes.

Changes in core values can induce institutional change and changes in (energy) policies $[9,10]$. For example, the value change from focusing on market efficiency towards affordability, security of supply, and sustainability in the European Union's energy policy led to legislation regarding renewable energy [11, 12]. Analyses of institutional change should account for this influence, but so far, a structured framework that highlights the role of values in institutional development is absent. This gap is all the more striking as the term "values" is mentioned by the core scholars who have developed and are working with the IAD framework. For example, scholars stress the importance that institutions "fit the values of those involved" [13, p. 16] and that shared values in a community will influence institutional development [14]. However, these accounts of values are limited to mentioning values in context with institutional change. Questions remain as to how "values" are defined, how to 
evaluate to what extent institutions are in line with values, how to elicit values of "those involved," or why and how shared values influence institutional development. Hence, structured approaches that go beyond mentioning and acknowledging that values might influence institutional change are still missing in IAD literature.

It is the aim of this paper to extend the dynamic IAD framework such that it can be used to analyze the role of values in institutional change. The resulting framework makes explicit how values are embedded in the material environment such as infrastructures, how they are embedded in existing institutions, how to elicit values shared by a community, how values influence behavior, and finally how they influence institutional change. To illustrate each of these potential ways how values can influence the elements of institutional change, we draw from the current transition to low-carbon energy systems as a case which we deem especially useful to highlight how changes in core values can induce policy changes. As already mentioned above, the value changes in EU energy policy from market efficiency to affordability, security of supply, and ecological sustainability during the first two decades of the twenty-first century led to changes in legislation, such as a greater interconnection of Europe's electricity networks, promotion of the use of energy from renewable sources, and many more $[11,12]$.

In order to extend the dynamic IAD framework by a value perspective, we take an interdisciplinary approach and review insights on values from moral philosophy, institutional economics, and social psychology. Since there is no unanimously agreed upon conceptualization of "values" in academic literature [15], we consciously take a broad approach and investigate how conceptions of values from different disciplines can complement the dynamic IAD framework. Thereby, the aim is not to develop a unified conceptualization of values. Rather, we will show how the disciplines with their different epistemological foundations can complement each other and each provide their own specific contribution to our framework. To the best of our knowledge, our paper is the first to analytically distinguish the different conceptions of "values" in these three disciplines and also combine those perspectives to highlight ways how values might influence institutional change.

In the next section, we start by introducing the basic analytical framework for institutional change: the dynamic IAD framework in which the original framework is expanded by social learning. Subsequently, the current value gap in IAD research is presented in further detail and we explain how this paper can contribute to fill this gap. In the subsequent section, we outline conceptualizations of values from the perspective of different academic fields. The discussion section synthesizes these theoretical perspectives and presents an analysis of the different roles of values for the single elements of the dynamic IAD framework. In order to illustrate the new framework, examples from the realm of the energy transition are chosen suitable for each element of the dynamic IAD framework.

\section{A dynamic framework for institutional change The Institutional Analysis and Development (IAD) framework}

The IAD framework, developed by Elinor Ostrom and her colleagues, is a framework that allows analyzing policy interventions and understanding how institutions develop [13] (Fig. 1). The framework identifies and describes important elements in decision-making situations within the policy process (so-called action situations) and how these are influenced by exogenous variables, such as the physical environment or laws and regulations [13]. The benefit of the IAD framework that makes it of special interest for this paper is its flexible applicability independent from the context of a specific sector. Rather than providing solutions, the framework raises important questions that help understanding the study problem and what potential solutions could be [16]. Therefore, it has been used in a variety of sectors, such as forestry, water management, fisheries, transportation systems, and others [4]. At the beginning of the framework development in the 1970s and 1980s, it has been applied to public administration and metropolitan organization, for example through empirical studies on police service in metropolitan areas $[4,17,18]$. More recently, the framework has increasingly been used in energy systems research. For example, Koster and Anderies [7] apply the IAD framework to compare the transition to renewable energy systems in four countries which were part of the top renewable energy users in 2012: Brazil, Spain, China, and the USA. They identify eight institutional drivers that contribute to the implementation of renewable energy, out of which the commitment of governments to set standards and provide financial incentives is found as the most important. Lammers and Heldeweg [1] use the IAD framework in an exploratory case study of local smart grid development. They enrich the IAD framework with institutional legal theory and show how the resulting framework can be used both for analytic description and prescriptive design of local smart grid systems. Another application of the IAD framework in context with the transition to renewable energy systems is the work by Shah and Niles [5] on Caribbean energy policy. The authors use the framework to analyze strengths and weaknesses of existing institutions and identify critical intervention points to reinforce or build institutions that promote a "clean energy transition." Additionally, Iychettira et al. [19] apply the IAD framework to understand the design and impact of governmental support schemes for renewable energy sources for electricity (RES-E). By 


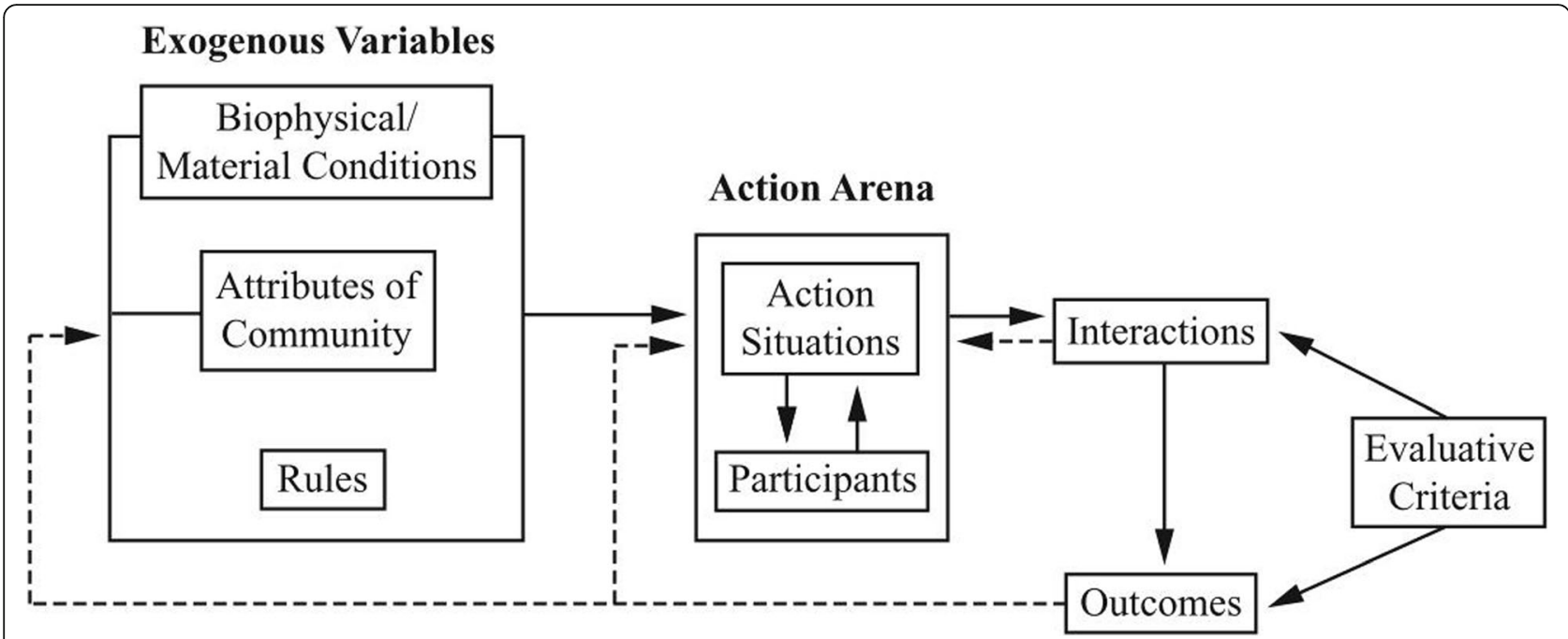

Fig. 1 Institutional Analysis and Development (IAD) Framework. Source: Ostrom [3]

distinguishing action situations at the level of government and energy producers, they use the IAD framework as basis for a simulation how support schemes for RES-E (developed by governments) impact investment in RES-E (by energy producers). This allows an understanding how specific support schemes (e.g., the German Premium Tariff or the British Contract for Differences schemes) contribute to renewable electricity targets [19].

The application of the IAD framework to a variety of topics as described above stems from the recognition that the framework offers a generic approach in analyzing public policies by diagnosing key elements of policy processes. It helps investigating important actors and their characteristics, rules that apply as well as the biophysical and socio-economic setting of a policy process [16]. As Heikkila and Andersson [16, p. 318] state: “... the IAD framework can provide a set of diagnostic questions for parsing out the key features of an institutional context that may affect policy outcomes." This structured way of analysis is very useful in tackling problems in highly complex systems, such as energy systems. Therefore, the IAD framework serves as the basic conceptual framework in this paper.

Within the IAD framework, institutions are defined as political, social, and legal "rules of the game" that incentivize (enable or restrict) actor behavior in situations which require coordination among two or more individuals or groups [4]. With this focus on institutions as rules, Elinor Ostrom's view on institutions is based on Douglass North, who defined them as the "humanly devised constraints that structure political, economic and social interaction" [20]. The definition differs from the common notion to understand the term institutions as a synonym for organizations. Institutions can be formal or informal: formal institutions are laws and regulations, such as prescriptions how and how much tax is added to energy prices; informal institutions, for example, in communication prescribe in many cultures that a speaker is listened to and not interrupted. For our case of the energy transition in this paper, we will focus on the formal rules that govern the energy system. Formal rules are of special relevance because the energy system is one of the critical infrastructures which constitute an important issue of national governance, sovereignty, and security.

The following paragraphs give an overview of the single elements of the IAD framework ${ }^{1}$. Broadly, the framework distinguishes exogenous variables, the action arena, interactions, evaluative criteria, and the outcome (Fig. 1). The element of action situations captures important or decisive events within a policy field (e.g., energy policy). Action situations are thus used in order to analyze human behavior within the institutional context [13]. "Action situations are the social spaces where individuals interact, exchange goods and services, solve problems, dominate one another, or fight [...]" [13, p. 11]. Thus, any analysis using the IAD framework starts by the identification of an action situation. The decision on what can be described as an action situation and what level of aggregation is best suited depends on the specific case study [22]. Using the IAD framework for an analysis of energy systems in this paper, the decarbonization of national energy systems constitutes the main problem that is addressed in various action situations, such as policy and innovation processes across vertical scales.

\footnotetext{
${ }^{1}$ The discussion section provides more detailed information about the IAD elements in order to combine them with different conceptualizations of values. Furthermore, readers might refer to $[3,4$, $13,14,21]$ for detailed descriptions of the framework.
} 
Participants of an action situation are human actors, who can be both individuals and organizations, such as governmental and non-governmental bodies or firms [13]. This means that actors become participants when they take part in an action situation. They are influenced by biophysical/material conditions, attributes of the community, as well as rules. The biophysical/material conditions are the physical environment in which an action situation is located. Attributes of the community describe the socio-economic characteristics of the community that forms the social environment of the action situation. Rules denote the institutional environment of an action situation, i.e., the formal laws and regulations that enable or constrain behavior of participants [3]. The outcome of an action situation as well as the process of interaction is assessed by various evaluative criteria, determined by the participants in action situations and those observing these situations. These criteria, for example, can be questions about sustainability, distributional equity, or conformance to other values [13].

\section{The IAD framework combined with social learning}

The main idea behind the IAD framework is breaking institutional development down to subsets consisting of various action situations [14]. Nevertheless, in terms of institutional change processes, the IAD framework reaches its limits. By focusing on separate action situations, institutional change cannot sufficiently be captured [16]. Even if the framework already includes feedback loops (see dotted lines in Fig. 1), thereby hinting that the evaluation of outcomes can have an influence on following action situations or the prevailing exogenous variables, it does not offer further explanation of this process. For this reason, this paper uses the dynamic version of the IAD framework as proposed by Pahl-Wostl et al. [23] including the concept of social learning. Like this, the IAD framework becomes process-oriented [22].

Social learning is a prominent concept in environmental and sustainability science that states that individuals learn and thereby increase the adaptive capacity of the system through their participation in decision-making $[24,25]$. Therefore, it can also serve as a valuable concept with regard to the transition towards low-carbon energy systems. However, many definitions of social learning exist so far [26-29]. In this paper, the definition of Reed et al. [24] is applied who state that "social learning may be defined as a change in understanding that goes beyond the individual to become situated within wider social units $[. .$.$] through social interactions be-$ tween actors within social networks." Hence, the concept of social learning is characterized by three qualities. Firstly, it comes with an alteration in understanding of those involved in the management of socio-technical systems. This can relate to attitudes, norms, or beliefs, i.e., mental models $[26,30]$. Thereby, ideas, experiences, and knowledge are shared among participants [25]. This transforms into a higher awareness for related issues and can eventually lead to appropriate action [28]. An outcome, for example, could be more sustainable patterns of behavior [24]. Secondly, this change of understanding needs to exceed the individual level and influence a wider social context. It is assumed that the complexities and uncertainties that come with regard to the management of natural resources require learning processes that go beyond the individual [27]. Like this, also social units, such as organizations, are able to learn as well, even if, in principle, only individuals possess the ability to learn, not do organizations per se [24]. Thirdly, social learning takes place through interaction within social networks [25]. These networks are embedded in and constraint by the technical, social, and institutional setting [26]. One way of interaction that can stimulate social learning are participatory processes $[24,30,31]$.

Generally, social learning can have three levels of impact. It can occur in the form of single-, double-, or triple-loop learning [32, 33]. Whereas single-loop learning is defined by an incremental adjustment of existing processes or goals, double-loop learning occurs when important principles underlying these processes are changed [34]. Double-loop learning causes changes in actor constellations and power structures [26]. Tripleloop learning requires changes in fundamental structures and norms [26]. The different levels of social learning are of special importance to the case of the energy transition since they describe if changes are rather superficial or have deeper impacts, such as structural changes.

Originally, the concept of double-loop learning stems from management theory and was mainly developed by Argyris and Schön [35]. Keen et al. [32] extended this concept by triple-loop learning which additionally alters the existing exogenous environment such as rules-inuse and biophysical/material conditions. Since the transaction costs resulting from institutional change can be very high, institutions and processes tend to be path-dependent. Therefore, political systems often only slowly adapt to altering environmental, political, and economic contexts $[8,36]$. Against this background, the three levels of single-, double-, and triple-loop learning often occur iteratively [8]. However, in order to profoundly change the way we generate, distribute, and consume energy, triple-loop learning seems to be necessary. Only by changing the exogenous variables, such as infrastructures, patterns of behavior, and institutions, current energy systems can adapt to the challenges of a low-carbon future.

Figure 2 illustrates how these levels of learning can be incorporated in the IAD framework. By using this 
definition of social learning, interrelations between subsequent action situations and impacts of prior action situations on changes in exogenous variables can be analyzed in greater detail than in the original IAD framework [22]. Table 1 summarizes the definitions of the elements of the framework and the different levels of learning.

\section{A value gap in IAD literature}

In its capacity to (a) analyze institutional change and (b) provide generic guidance what structural variables are present in processes of institutional development, the dynamic IAD framework forms a suitable basis for our aim of explicating how values influence institutional change processes. Structured approaches to analyze this influence, however, are so far missing, even though the term "values" is mentioned quite frequently by the scholars who have developed and are working with the IAD framework. Ostrom herself stressed the importance of an evaluation how institutions "fit the values of those involved" in their development [13, p. 16]. McGinnis [14] mentions that the development of institutions will be influenced by the degree to which members of a community developing an institution share the same core values. Others acknowledge that human behavior cannot be fully understood when only focusing on material selfinterest as a driver, but that values influence human behavior and thus also the development of institutions [37, 38]. A first effort to go beyond merely acknowledging and mentioning values has recently been undertaken by Prior [39] in the context of the removal of pollutants from contaminated soil, sediment, and water. Using Schwartz' value framework [40, 41], Prior [39] finds that different stakeholders are motivated by different values to comply with existing institutions. For example, local governments are motivated by universalist values (concern for welfare and equity) while providers of services to remove the pollutants are motivated by achievement and power values (power and success). However, this is still limited in its focus on individuals' values, compliance with existing institutions, and conceptualization of values from one academic discipline, namely social psychology.

\section{Multi-disciplinary conceptualizations of "values"}

In light of the value gap in the IAD literature identified in the previous section, there is a need to define and conceptualize "values" before we can build our framework. In general, values can be defined as fundamental normative guiding principles to which changes in a society should adhere and which are considered to be intersubjectively shared [42]. Beyond such a general definition, however, the concept has been used differently across academic disciplines, and debates are often characterized by conceptual struggles and vagueness $[15,43,44]$.

Therefore, this section sets out to investigate possible literature perspectives that can be useful to integrate values into the dynamic IAD framework. Starting from first efforts of integrating values in the IAD framework by Prior [39], we observed in the previous section that he makes use of an account of values used in social psychology. We also draw from institutional economics as the original discipline in which the IAD framework was developed and in which recent work addresses the relation between values and institutions. Additionally, we review the notion of values in moral philosophy, which has probably the longest tradition of reflecting on values. We will show that these conceptualizations of values can enhance the dynamic IAD framework in a

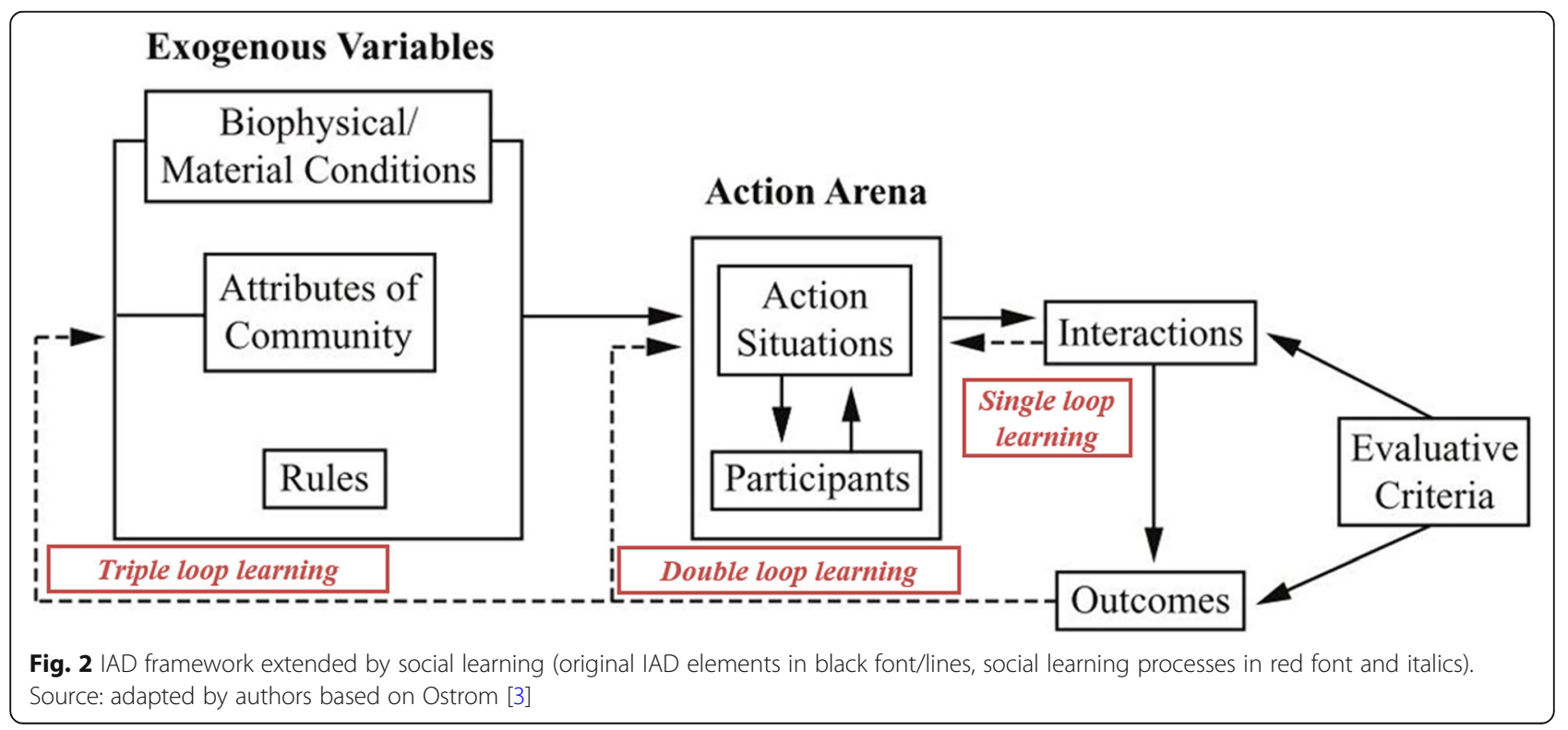


Table 1 Definitions of the elements of the IAD framework extended by social learning

\begin{tabular}{|c|c|c|}
\hline Framework element & Definition & Source \\
\hline $\begin{array}{l}\text { Biophysical/Material } \\
\text { Conditions }\end{array}$ & Physical environment influencing possible actions taken in action situations, e.g., existing infrastructure & McGinnis [14] \\
\hline $\begin{array}{l}\text { Attributes of } \\
\text { Community }\end{array}$ & Socio-economic characteristics of the participants' community & Ostrom et al. [21] \\
\hline Rules & Institutions, e.g., formal laws and regulations that enable and constrain behavior of participants & Ostrom [3] \\
\hline Action Situation & $\begin{array}{l}\text { Social space of interaction, in which participants decide on their individual actions given the } \\
\text { information they have about how those actions lead to outcomes and the costs and benefits } \\
\text { associated with those actions and outcomes }\end{array}$ & McGinnis [14] \\
\hline Participants & Individual actors or actor groups, e.g., governmental and non-governmental bodies or firms & Ostrom [13] \\
\hline Interactions & Procedural aspects, i.e., interaction among participants in an action situation & Ostrom et al. [21] \\
\hline Outcomes & $\begin{array}{l}\text { Results of interactions, which may be institutions, knowledge, or operational outcomes such as } \\
\text { the implementation of new technologies }\end{array}$ & Pahl-Wostl et al. [23] \\
\hline Evaluative Criteria & $\begin{array}{l}\text { Criteria that are used to assess interactions and outcomes, e.g., sustainability, distributional equity, } \\
\text { economic efficiency }\end{array}$ & Ostrom [13] \\
\hline $\begin{array}{l}\text { Feedback and learning } \\
\text { processes }\end{array}$ & $\begin{array}{l}\text { Impact of actors' evaluations of interaction patterns and outcomes on action situation and } \\
\text { exogenous variables }\end{array}$ & McGinnis [14] \\
\hline Single loop learning & Process leading to an incremental adjustment of patterns of interactions within one policy process & Diduck et al. [34] \\
\hline Double loop learning & $\begin{array}{l}\text { Process leading to change of principles that underlie future action situations, e.g., procedural } \\
\text { aspects of decision-making }\end{array}$ & Diduck et al. [34] \\
\hline Triple loop learning & Process leading to changes in the existing exogenous variables & Armitage et al. [26] \\
\hline
\end{tabular}

complementary way and contribute to a more encompassing understanding how values might influence institutional change. The three perspectives are outlined below. Combined with the dynamic IAD framework, they will be used in the discussion section to explicate the role of values for institutional change.

\section{Values in moral philosophy}

In moral philosophy, values are criteria to make statements about the ethical goodness of options for action. They are normative human principles worth striving for. Central questions include for example: "How should I live my life?" or "What is the right thing to do in this situation?" [45, p. 12]. Values are considered to be intersubjectively shared, that means different individuals can relate to a value and generally hold it important [46, 47]. In ethics of technology, values are analogously used to make statements about ethical and social consequences of technologies. Typical values relevant for energy systems, just to state a few, are affordability of energy, security of supply, health, environmental sustainability, and justice [48]. Central questions include "What types of values do technological artifacts have or contribute to? How are value considerations inherent to design choices?" [46, p. 973]. This highlights that values are seen as identifiable entities that are embedded in technologies.

Evaluating technologies in light of value embeddedness is grounded in the understanding that they are not mere neutral objects or instruments for humans in moral decision-making [49]. Technologies are value-laden and thus capable of endorsing or harming specific values [50]. In his seminal article on the politics of artifacts, Winner [50] gives the much-cited example of very low overpasses over the only highway connecting New York with Long Island Beach, thereby hindering public busses (the main method of transportation for less well-off societal groups including racial minorities) to access the beach. Although the truth of this example has been debated, for example by Joerges [51], it is often used to illustrate the moral importance of technological design in the sense that technologies tend to represent certain dominant values while failing to embed others $[52,53]$.

Assigning moral significance to technology does not mean that technology in itself has agency and humans have no responsibility. As Verbeek [49] argues, technology mediates human perceptions on the basis of which moral decisions are made. To explain technological mediation, Verbeek [49] points out how picturing an unborn baby through ultrasound enables to discover illnesses and constitutes parents as decision-makers over the life of the unborn.

Making technological mediation explicit and recognizing that moral decisions are based on a deep connection between humans and technologies allows designing technologies consciously with specific values in mind. Furthermore, it allows recognizing the importance of the use context: technologies are multistable, meaning that they can be interpreted and used in various ways, including for purposes that were not intended by designers [54]. The social context of the use or users of 
technologies may thus give rise to new behavior and lead to the emergence of new values and value changes [55, 56]. This opens the door for understanding ethics of technology not as "protecting humans against technology," but as careful experimentation with technological mediation in order to experience how values are embedded in different technological designs [49].

\section{Values in institutional economics}

In institutional economics (IE), values are seen as influencing the behavior of economic actors and as embedded in institutions, such as laws and regulations. Although values are usually not a central topic to institutional economists, recent literature does provide conceptualizations and addresses the relation between values and institutions $[10$, $43,57]$. In general, IE emerged based on critiques of the pure focus on perfect markets and full rationality in neoclassical economics. It broadens economic analysis by looking at institutions and trying to understand how they influence human behavior and how they emerge [58]. Decisions are not solely dependent on utility maximization and efficiency is not the ultimate objective to strive for. Actions also depend on positive or negative impacts of more divergent values which are seen as important in a society [10]. As such, values are seen as normative guidelines and criteria for decision-making $[43,58]$. Additionally, values influence the design of formal institutions (e.g., the formal "rules of the game") [59]. In the distinction between formal and informal institutions (see the "The Institutional Analysis and Development (IAD) framework" section), values are seen as informal institutions, which set the boundaries within which formal institutions are developed [57, 59]. Formal institutions are therefore not valuefree; they should endorse those specific values they have been designed for. For example, laws and regulations are designed to serve a certain purpose, e.g., the expansion of renewable energies. Usually, specific values underlie this purpose. In the case of renewable energies, protection of nature would be one of these values. Additionally, other values might be embedded in institutions unconsciously by policy makers.

\section{Values in social psychology}

In social psychology, values are studied as personality characteristics that influence human decision-making and behavior [60]. Values are "(a) concepts or beliefs, (b) about desirable end states or behaviors, (c) that transcend specific situations, (d) guide selection or evaluation of behavior and events, and (e) are ordered by relative importance" [41, p. 551].

Extensive theoretical and empirical work on conceptualizing and measuring values has been conducted based on the seminal contributions of researchers like Schwartz, Bilsky, and Rokeach (for reviews, see [44, 61]).
Schwartz $[40,41]$ is known for the development of the most commonly used measurement of values, the socalled Schwartz Value Survey. The survey consists of 56 items to measure individuals' value priorities, grouped in ten value orientations. These include, for example, selfdirection (e.g., freedom, independence, self-respect), achievement (e.g., success, ambition, intelligence), power (e.g., wealth, authority, public image), or universalism (e.g., equality, wisdom, social justice) [40]. This approach to measuring individuals' values has recently been used within the IAD literature by Prior [39] to study why individuals comply with existing institutions that regulate the remediation of contaminated environments. Prior [39] found that local governments are influenced by universalist values while remediation providers are influenced by achievement values. Besides the Schwartz Value Survey, there are of course several other influential surveys measuring individuals' value priorities and value orientations. The details are out of scope for this text, but for further reading, Cheng and Fleischmann [61] give a good overview of different conceptualizations and lists of values in an attempt to create a metainventory of human values.

\section{Discussion: adding a value perspective to the dynamic IAD framework}

A consideration of underlying values and their role for institutional change requires an expansion of the dynamic IAD framework. We use the conceptualization of values in different disciplines outlined above to illustrate the role of values in the framework elements. The following paragraphs describe what role values play for the single elements of the dynamic IAD framework and outline how they are related to different conceptualizations of values. Our analytical approach comprises of three steps (Fig. 3). Firstly, we define the constituting elements of the dynamic IAD framework. Secondly, we highlight the relevant conceptualization of values applicable to the specific element, and thirdly, we combine the first two steps in examples from the energy transition. The results of our analysis are summarized in Fig. 4.

\section{Participants}

Since any transition process involves people taking action, our analysis starts at the element of participants. Participants can act as individuals or groups representing an entity. Ostrom defines participants as fallible learners that not only can, but actually make mistakes and have the ability to learn from these mistakes. If and how an actor learns is thus dependent on the incentives and possibilities provided by the institutional setting. Generally speaking, action choices are always influenced by the exogenous variables [13]. 


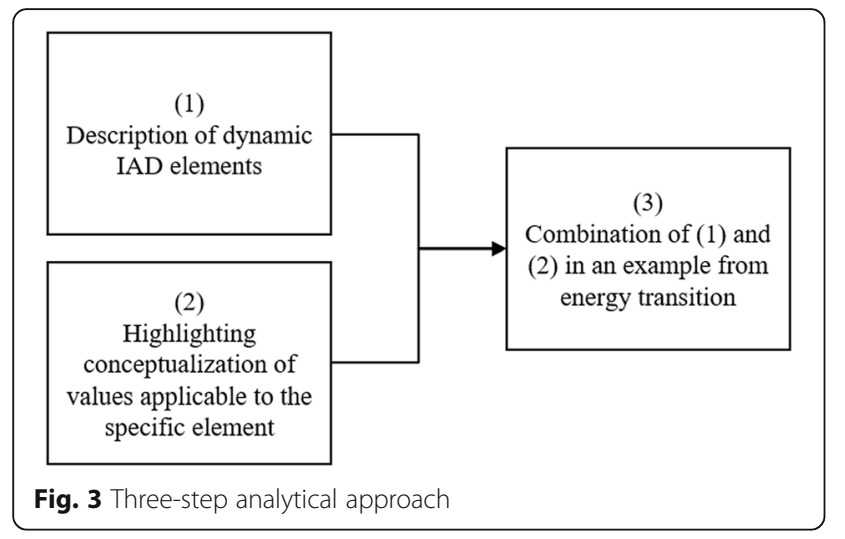

Assuming that human behavior is driven by personal or professional characteristics and attributes-depending on the role the participant is acting in-the psychological definition of values can deliver important implications for behavior regarding energy systems. Values work as principles influencing or driving human behavior and are thus specific characteristics of personality [40].

To exemplify that influence, we draw from a study by van der Werff and Steg [62], who investigated the effects of biospheric values (e.g., valuing unity with nature and environmental protection), egoistic values (e.g., valuing wealth and social power), altruistic values (e.g., valuing social justice and helpfulness), and hedonic values (e.g., valuing comfort and pleasure) on interest and participation in smart energy systems. They found that people with strong biospheric values were more interested in smart energy systems and more likely to participate in a proposed pilot project because they were more aware of environmental problems of fossil fuels, had stronger feelings that they could contribute to solving those problems by participating in smart energy systems, and felt a stronger moral obligation to solve those problems. Interest was more strongly influenced by biospheric values than actual participation. Participation was also influenced by egoistic and hedonic values, suggesting that concerns about effort and money negatively influenced the likelihood of people participating in smart energy systems. Regarding the IAD framework and institutional change, this implies that, depending on the participants involved in an action situation, individuals' values-referring to social psychology—can influence what technologies are preferred by participants and how those technologies are discussed in an action situation.

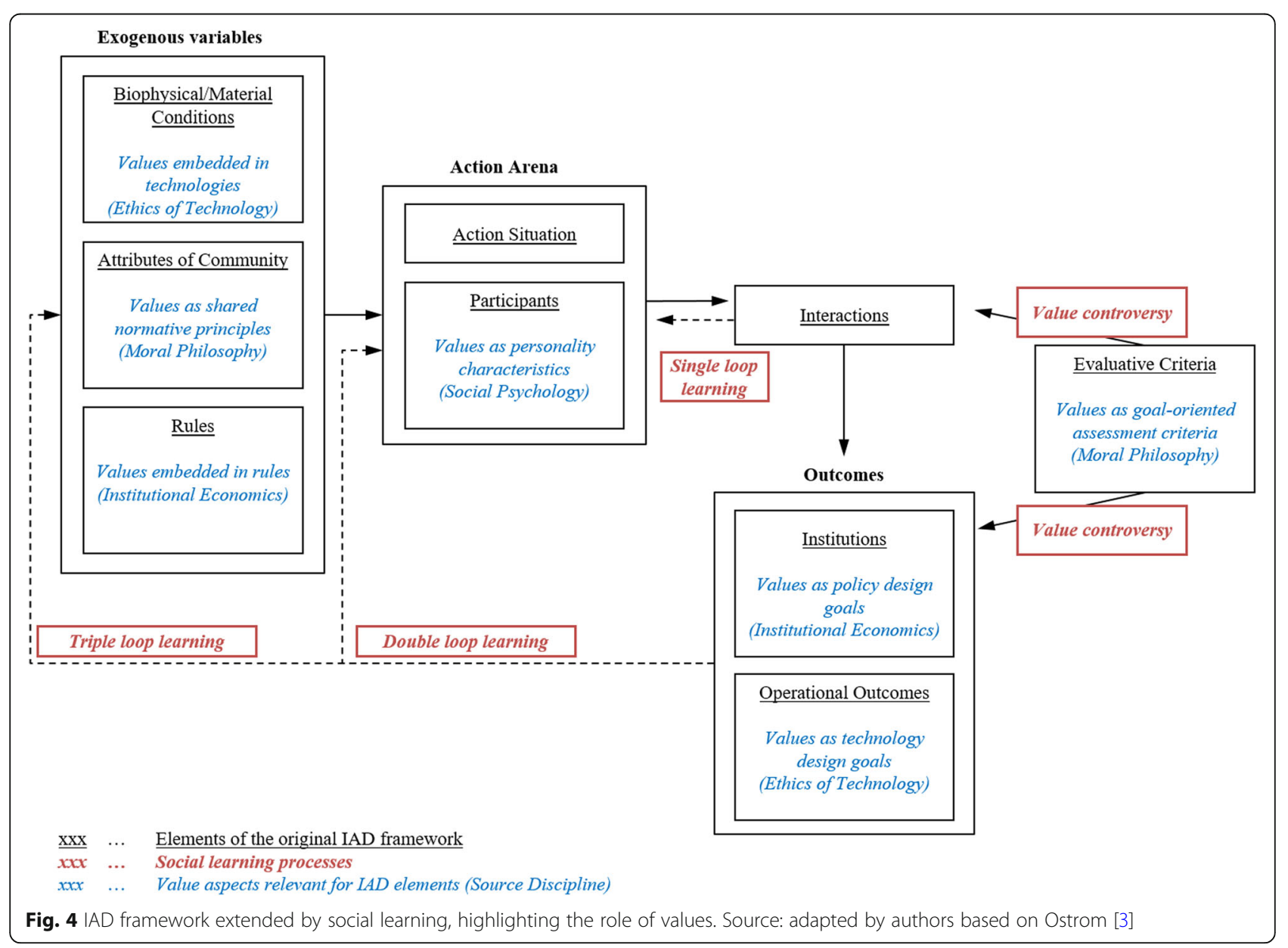




\section{Evaluative criteria for outcomes and patterns of interaction}

The conceptualization of values in ethics of technology and IE allows us to outline the role of values as evaluative criteria for outcomes and patterns of interactions. Since Ostrom does not offer an explanation of what outcomes can look like, we apply the broader definition of PahlWostl et al. [23], who defined three types of possible outcomes of action situations: institutions, knowledge, and operational outcomes. The latter, for example, also captures the innovation of new technologies, which is of special importance for energy systems.

In the context of new technologies, the definition of values from ethics of technology offers important implications. Values can be used to define and design essential characteristics of technologies. This is grounded in the understanding that technologies cannot be seen as neutral objects but are value-laden $[50,63]$. In the same way, values can serve as design principles and characteristics of institutions. This implication, however, mostly derives from IE: values are influential for institutional change and become embedded in institutions through value judgments [64].

To assess the performance of a system, outcomes as well as patterns of interactions are judged by specific evaluative criteria. Ostrom names different types of these criteria, e.g., economic efficiency, accountability, or fiscal equivalence. In the case of the energy transition, sustainability, or distributional equity are critical [13]. When giving those examples for evaluative criteria, Ostrom [3] does not explicitly call them "values," but the examples are in fact values as they are defined in moral philosophy: goal-oriented assessment criteria and normative principles that are worth striving for and that institutional developments should adhere to [65].

Two examples highlight how values can serve as evaluative criteria for outcomes and interaction patterns. Firstly, if the focus of an action situation is to incentivize investment in renewable energy technologies, the outcome (i.e., the actual investment in renewables) can be assessed using values as evaluative criteria. A hypothetical region A with a high degree of small-scale solar power might be compared with region $B$ with a focus on hydropower. Region A is likely to incorporate the values "consumer empowerment" and "participation" in energy generation to a higher degree, while this might come at the expense of system reliability due to a higher degree of intermittent supply. Region B is likely to focus on values of emission-free, large-scale, relatively secure energy supply, while this might come at the expense of local ecosystems near hydropower dams.

Secondly, and with regard to interaction patterns, the degree to which a variety of stakeholder groups is integrated in decision-making processes on the siting of wind parks (i.e., the degree of procedural justice) might impact the acceptance of the wind park by local communities [66]. This means that depending on where the action situation is located, the selection of participants will have an influence on the outcome. However, it will also influence an assessment to what extent core values were considered and, in the end, if certain technological or institutional changes are accepted or not.

\section{Biophysical/material conditions}

The biophysical/material conditions in the IAD framework describe the physical environment in which an action situation is located [3]. It includes the physical and human resources needed to produce and provide goods and services, such as capital, labor, technology, sources of finance, and distribution channels [4]. The biophysical/ material conditions include the humanly devised technologies to generate, distribute, and consume energy.

Research in ethics of technology allows identifying how values are linked to attributes of the biophysical world. Values are embedded in the technologies to generate, distribute, and consume energy through the design and use of these technologies. As values are seen as design goals, engineers create technologies with the aim to incorporate specific values, such as health and safety or security of supply [52]. Ethicists analyze the moral repercussions of using certain technologies because technologies do not only fulfill the specific function they are designed for but can have unintended side-effects [67].

To exemplify the relation between values and technologies, we look at the value implications of hydropower dams: large hydropower dams are considered a low carbon energy source that can provide access to energy for millions of people and are thus seen as affordable renewable energy. Targets to lower carbon emissions and increase energy access have therefore led to a renaissance of large hydropower developments particularly in Africa and Asia [68]. Despite their importance for energy access, important moral repercussions include protection of the river ecosystem and distributive justice, particularly with respect to the effects on downstream water supply and the fair distribution of water along the entire river basin. Studying three large hydropower dams in Cambodia, Malaysia, and Ghana, Siciliano and Urban [69] investigate the dams' impacts on local communities with respect to procedural and distributive justice in the allocation of natural resources between competing users and land uses. From a distributive perspective, their findings reveal that beneficiaries of the dam are the dam builders, recipients of electricity in urban areas, and national governments because of improved energy access statistics on a national level. However, local communities were threatened in their livelihoods because of adverse effects on forestry resources, fisheries, and water supply. Procedurally, the 
limited consultation of local communities by dam builders and national government agencies illustrate the unequal power relations between those groups. The example highlights that energy technologies can implicate a range of values, which should be taken into account in their design and implementation.

\section{Attributes of community}

Attributes of the community are described in order to capture characteristics of the participants of the focal action situation [4, 70]. Attributes that are important in affecting action situations include values or behavior generally accepted in the community, the level of common understanding about the structure of types of action situations, the degree of homo-/heterogeneity in preferences, the size and composition of the community, and the extent of inequality of distribution of basic assets among those affected.

Even though values are mentioned in literature on the IAD framework as part of the attributes of a community, a definition and explanation is lacking. Insights from moral philosophy are helpful to explain them in greater detail: values are shared normative principles about what is a good and right development in a given community or society $[46,47]$. The degree to which different values are seen as important in a community will impact the potential outcomes in an action situation and the actual outcome that participants decide upon.

An example of such shared normative principles for energy policy that need to be considered in an institutional analysis can be seen in the three focus objectives of the European Union's energy strategy and policy: security of energy supply, affordability of energy for consumers, and environmental sustainability [71]. It strives to "secure energy supplies to ensure the reliable provision of energy whenever and wherever it is needed," ensure "affordable prices for homes, businesses, and industries," and achieve energy consumption that is "sustainable, through the lowering of greenhouse gas emissions, pollution, and fossil fuel dependence" [71]. This was not always the case: until approximately halfway through the first decade of the twenty-first century, European energy policy was dominated by the goal to create efficient energy markets through increased competition. However, as policy makers were increasingly recognizing the threats associated with anthropogenic climate change and the need to decarbonize the energy system, the reduction of carbon emissions by moving away from the use of fossil fuels became an important goal for European policy making [10]. This shows how changing normative values can affect and broaden policy objectives considered in an action situation.

\section{Rules}

The most accepted and shared definition of institutions focuses on institutions as "rules of the game" and systems of rules which enable and constrain actor behavior $[3,72]$ (see the "A dynamic framework for institutional change" section). Rules in the IAD framework are prescriptions which define whether actions are required, prohibited, or permitted. Importantly, the focus lies on rules-in-use which are rules that are known to the participants in an action situation and thus have the capacity to influence their behavior. They are differentiated from rules-in-form, which are unknown to the participants in an action situation [13]. In an open and democratic society, the origin of rules can be very diverse ranging from a group of individuals to decide on their own rules for an action situation, families, and workplaces, to firms, local and regional governments, national governments, and supra-national organizations [13]. In short, rules in the IAD framework denote the exogenous institutional environment of an action situation.

Values are influential for institutional change and seen as entities that are embedded in institutions [10]. Because of this, the exogenous rules-in-use shaping an action situation will embed the values they have been previously designed for. In a similar way as values are seen as embedded in technologies, rules are value-laden. Essentially, institutional economists view a change of rules as a change of value judgment by the community involved in creating rules (i.e., a change of the degree to which different values are seen as important and should be used as guiding principles for designing a rule) [58].

The example of European energy policy mentioned in the "Attributes of community" section can be extended to illustrate how values become embedded in rules. Because of the shared understanding of the importance of security of energy supply, affordability of energy for consumers, and environmental sustainability, these three values have become the most important objectives that European energy policy is directed at. For example, as the value of environmental sustainability was operationalized by European energy policy makers in terms of the reduction of carbon dioxide emissions, it got embedded in the design of a range of policies, such as the European Emissions Trading Scheme, national support schemes for wind and solar power generation, or rules for the energy performance of buildings $[10,12]$.

\section{Social learning through value controversies}

The concept of social learning explains how institutional change occurs (see "The IAD framework combined with social learning" section). Social learning is never value free [26] and can be induced by value controversies [73]. Values can become apparent in controversies concerning the formal policy process, as institutional change may have different impacts on different groups of people and therefore raise questions of redistribution of responsibilities and risks. Defenders of the status quo may refer to 
different values than defenders of the proponents of change. In the language of the dynamic IAD framework, different evaluative criteria used by different participants can trigger social learning processes.

Value controversies may become expressed in the form of social interaction within governmental or nongovernmental actor networks, such as public debates [9]. They are closely connected to double- and triple-loop learning, as they usually occur outside of the formal policy development process: value controversies are expressed in public debates, which can put pressure on existing formal rules and thus trigger structural change. The types of learning in which non-governmental participants, e.g., NGOs, associations, and trade unions, get involved, are referred to as double- and triple-loop learning [8]. Especially in cases of major societal transformation processes like the energy transition, non-governmental participants play a vital role. They can provide governmental participants with additional knowledge useful for assessing problems and creating innovative solutions. Figure 4 summarizes all extensions made to the original IAD framework including the concept of value controversies.

Pesch et al. [9] give examples for value controversies leading to double- and triple-loop learning in the Dutch Energy system. In case of a planned shale gas extraction in Boxtel, an already granted permit was revoked after local citizens and companies mobilized national NGOs and advocacy groups. A resulting national anti-shale gas movement led not only to the withdrawal of the actual exploration permit but also to a prohibition of new exploration permits pending further research studies that explicitly include local concerns. Another example refers to a planned carbon capture and storage facility in the municipality of Barendrecht, where local resistance and high media attention, followed by a change in government led to the abandoning of the project. In both cases, value controversies were based on safety concerns, distrust between the local population and political and economic actors, as well as on an inadequate participation of the local population in formal permitting processes. These two cases, in combination with an increasing numbers of earthquakes near the country's major gas field in Groningen, eventually led to changes in the prevailing national institutional setting, namely the Dutch Mining Act. The controversies led to a decrease in public confidence towards political and economic actors, and to questioning the adequacy of the prevailing rules provided by the Dutch Mining Act, particularly rules regarding citizen participation. These reservations were acknowledged and articulated by various governmental actors and in the end led to a profound adjustment of the Mining Act regarding safety issues and the involvement of local authorities [9]. The examples demonstrate how social learning processes occur incrementally and can reinforce each other culminating in changes of the exogenous variables, which can be defined as tripleloop-learning.

\section{Conclusion}

In this paper, we proposed a dynamic framework for analyzing the role of values in institutional change. The energy transition serves as a valid example showing that changes in (energy) policies can be induced by changes in core values. Thus, understanding how values become incorporated in (energy) policies is an important challenge for the analysis of institutional change. Up to now, such an analysis has been hindered by the absence of a framework that highlights the role of values. Therefore, we built on a dynamic IAD framework-a combination of the original IAD framework and social learning-and enhanced it by using conceptualizations and insights on values from different academic disciplines: moral philosophy, institutional economics, and social psychology. In the resulting framework, the roles of values for different IAD framework elements and feedback loops are explicitly highlighted.

The framework makes explicit how values influence the behavior of participants in an action situation and how they are used as evaluative criteria for patterns of interaction and outcomes of an action situation. Values are embedded in the biophysical/material conditions such as infrastructures as well as in the rules creating the institutional environment of an action situation. In addition, they are shared principles of what is good and right in a given community. We also showed how value controversies can trigger institutional change by inducing social learning. These learning processes can have different levels of impact. In their most prominent form, they can lead to changes in the exogenous variables with respect to the creation of value-laden technologies and institutions as well as community attributes. Since these exogenous variables are thereby related to previous action situations, the new framework helps connecting action situations and explains when and how institutional change occurs due to social learning [74].

While developing the framework, we showed that the three perspectives on values are complementary: Each of the disciplines offers their own distinctive conceptualization of values that can be used to explain different aspects of institutional change. The psychological perspective-previously used in IAD literature [39]-directs attention at individuals' motivations by investigating how values and value orientations influence human behavior. As such, this perspective on values would be suitable to understand why policy makers or other participants in an action situation prefer certain institutions over others, for example depending on their biospheric, altruistic, and/or egoistic value orientations. Philosophers of technology particularly direct 
attention to the embeddedness of values in technologies and to values as normative criteria for comparing the design and performance of energy systems, making this perspective useful to understand the relation between values and (technological) design. Recent literature in institutional economics is inspired by ethics of technology and the idea of value embeddedness, arguing that institutions can foster or harm certain values and that they can be designed and analyzed with respect to those values. It therefore contributes to the understanding of relations between values and institutions.

Both researchers and policy makers can use our framework to analyze institutional change. It can help to explain how different values become relevant triggered by societal controversies and how this influences the change of shared values and institutions. Apart from this longitudinal perspective, our framework also allows cross-sectional, comparative analysis of different energy systems because values serve as evaluative criteria for different system designs. It allows comparison of change patterns across geographies and time spans such as speed of transitions, enablers and barriers, or the openness of formal learning processes. Both longitudinal and cross-sectional analyses can serve as input for changes in the design of energy systems in different temporal and spatial contexts.

Future research and practical applications of the framework could thus be done with respect to a specific case study of institutional change in energy systems. When doing so, we would advise to select a value perspective as depicted in Fig. 4 that best fits the research focus. For example, if the purpose of a study is to compare national energy regulation (e.g., subsidies for energy generation), one might focus on the IAD framework element "rules" and the values' perspective in institutional economics. If interested in ethical reflections of technological design (e.g., of wind turbines), the element "evaluative criteria" together with value conceptions in philosophy are a suitable choice.

We acknowledge that a complete analysis of values in institutional change in the energy transition would necessitate additional tools and research. Most importantly, such an analysis needs to include an elicitation, conceptualization, and operationalization of the relevant values, which are specific to the technological, institutional, temporal, and spatial context. This might include the development of indicators to measure the embeddedness of values in different energy systems. In this paper, we provided the basic framework for such research and concentrated on the conceptual foundation that enables a value-based analysis of institutional change in general and is open to include a variety of relevant values.

\section{Abbreviations}

IAD framework: Institutional Analysis and Development framework; IE: Institutional economics

\section{Acknowledgements}

The idea and analytical approach in this paper was developed during the "SHAPE ENERGY Research Design Challenge," March 2018 (https:// shapeenergy.eu). The authors like to thank Sandra Venghaus and Neelke Doorn for valuable comments on previous versions of this article.

\section{Authors' contributions}

The article's concept and main messages were developed in joint discussions. The first and second author (CM and $\mathrm{CM}$ ) contributed equally to the article. HS, RK, and GK gave input on several drafts. All authors read, revised, and approved the final manuscript.

\section{Funding}

This work was supported by the Netherlands Organization for Scientific Research (NWO) under the Responsible Innovation Program [Grant No. 31399-305]. The funding body did not have any role in the design and writing of the manuscript.

\section{Availability of data and materials}

Not applicable

Ethics approval and consent to participate

Not applicable

\section{Consent for publication}

Not applicable

\section{Competing interests}

The authors declare that they have no competing interests

\section{Author details}

${ }^{1}$ Faculty of Technology, Policy and Management, Delft University of Technology, Jaffalaan 5, 2628 BX Delft, Netherlands. ${ }^{2}$ Institute of Energy and Climate Research, Forschungszentrum Jülich GmbH, Jülich 52425, Germany.

Received: 15 May 2019 Accepted: 2 December 2019

Received: 15 May 2019 Accepted: 2 Decem

References

1. Lammers I, Heldeweg MA (2016) Smart design rules for smart grids: analysing local smart grid development through an empirico-legal institutional lens. Energy Sustain Soc 6. https://doi.org/10.1186/s13705016-0102-z

2. Hoppe T, Coenen F, van den Berg M (2016) Illustrating the use of concepts from the discipline of policy studies in energy research: an explorative literature review. Energy Res Soc Sci 21:12-32. https://doi.org/10.1016/j.erss. 2016.06.006

3. Ostrom E (2005) Understanding institutional diversity. Princeton University Press, Princeton, New Jersey

4. Polski MM, Ostrom E (1999) An institutional framework for policy analysis and design. In: Cole DH, MD MG (eds) Elinor Ostrom and the Bloomington School of Political Economy: A Framework for Policy Analysis. Lexington Books, Lanham, Md, pp 13-47

5. Shah KU, Niles K (2016) Energy policy in the Caribbean green economy context and the Institutional Analysis and Design (IAD) framework as a proposed tool for its development. Energy Policy 98:768-777. https://doi. org/10.1016/j.enpol.2016.07.045

6. Iychettira KK, Hakvoort RA, Linares P, de Jeu R (2017) Towards a comprehensive policy for electricity from renewable energy: designing for social welfare. Appl Energy 187:228-242. https://doi.org/10.1016/j.apenergy. 2016.11.035

7. Koster AM, Anderies JM (2013) Institutional factors that determine energy transitions: a comparative case study approach. In: Michalena E, Hills JM (eds) Renewable energy governance: Lecture Notes in Energy 23. Springer, London, UK

8. Pahl-Wostl C (2009) A conceptual framework for analysing adaptive capacity and multi-level learning processes in resource governance regimes. Glob Environ Chang 19:354-365. https://doi.org/10.1016/j.gloenvcha.2009.06.001

9. Pesch U, Correljé A, Cuppen E, Taebi B (2017) Energy justice and controversies: formal and informal assessment in energy projects. Energy Policy 109:825-834. https://doi.org/10.1016/j.enpol.2017.06.040 
10. Correljé A, Groenewegen J, Künneke RW, Scholten DJ (2015) Design for values in economics. In: van den Hoven J, Vermaas PE, van de Poel I (eds) Handbook of Ethics, Values, and Technological Design: Sources, Theory. Values and Application Domains. Springer Netherlands, Dordrecht, pp 639-666

11. Correljé A, Cuppen E, Dignum M, et al (2015) Responsible innovation in energy projects: values in the design of technologies, institutions and stakeholder interactions. In: Koops B-J, Oosterlaken I, Romijn H, et al (eds)Responsible Innovation 2, Concepts, Approaches, and Applications. Springer International Publishing, pp 183-200

12. EUR-Lex (2018) Energy. https://eur-lex.europa.eu/summary/chapter/energy. html?root_default = SUM_1_CODED\%3D18

13. Ostrom E (2011) Background on the institutional analysis and development framework. Policy Stud J 39:7-27. https://doi.org/10.1111/j. 1541-0072.2010.00394.x

14. McGinnis MD (2011) An introduction to IAD and the language of the Ostrom workshop: a simple guide to a complex framework. Policy Stud J 39:169-183. https://doi.org/10.1111/j.1541-0072.2010.00401.x

15. Kroes P, Van de Poel I (2015) Design for values and the definition, specification, and operationalization of values. In: van den Hoven J, Vermaas PE, van de Poel I (eds) Handbook of Ethics, Values, and Technological Design: Sources, Theory. Values and Application Domains. Springer Netherlands, Dordrecht, pp 151-178

16. Heikkila T, Andersson K (2018) Policy design and the added-value of the institutional analysis development framework. Policy Polit 46:309-324. https://doi.org/10.1332/030557318X15230060131727

17. Ostrom E (1972) Metropolitan reform: propositions derived from two traditions. Soc. Sci. Q. 53:474-493

18. Ostrom V, Ostrom E (1971) Public choice: a different approach to the study of public administration. Public Adm Rev 31:203. https://doi.org/10.2307/974676

19. lychettira KK, Hakvoort RA, Linares (2017) Towards a comprehensive policy for electricity from renewable energy: an approach for policy design. Energy Policy 106:169-182

20. North DC (1991) Institutions. J Econ Perspect 5:97-112. https://doi.org/10. 1257/jep.5.1.97

21. Ostrom E, Gardner R, Walker J (1994) Rules, games, and common-pool resources. University of Michigan Press, Ann Arbor, Michigan

22. Pahl-Wostl C, Becker G, Sendzimir J, Knieper C (2013) How multi-level societal learning processes facilitate transformative change: a comparative case study analysis on flood management. Ecol Soc 18:58. https://doi.org/ 10.5751/ES-05779-180458 Research

23. Pahl-Wostl C, Holtz G, Kastens B, Knieper C (2010) Analyzing complex water governance regimes: the management and transition framework. Environ Sci Policy 13:571-581. https://doi.org/10.1016/j.envsci.2010.08.006

24. Reed MS, Evely AC, Cundill G et al (2010) What is social learning? Ecol Soc 15:r1. https://doi.org/10.5751/ES-03564-1504r01

25. Berkes $F$ (2009) Evolution of co-management: role of knowledge generation, bridging organizations and social learning. J Environ Manage 90:1692-1702. https://doi.org/10.1016/j.jenvman.2008.12.001

26. Armitage D, Marschke M, Plummer R (2008) Adaptive co-management and the paradox of learning. Glob Environ Chang 18:86-98. https://doi.org/10. 1016/j.gloenvcha.2007.07.002

27. Blackmore C (2007) What kinds of knowledge, knowing and learning are required for addressing resource dilemmas?: a theoretical overview. Environ Sci Policy 10:512-525. https://doi.org/10.1016/j.envsci.2007.02.007

28. Cundill G, Fabricius C (2009) Monitoring in adaptive co-management: toward a learning based approach. J Environ Manage 90:3205-3211. https:// doi.org/10.1016/j.jenvman.2009.05.012

29. Rodela R (2011) Social learning and natural resource management: the emergence of three research perspectives. Ecol Soc 16. https://doi.org/10. 5751/ES-04554-160430

30. Scholz G, Dewulf A, Pahl-Wostl C (2014) An analytical framework of social learning facilitated by participatory methods. Syst Pract Action Res 27:575591. https://doi.org/10.1007/s11213-013-9310-z

31. Cundill G, Rodela R (2012) A review of assertions about the processes and outcomes of social learning in natural resource management. J Environ Manage 113:7-14. https://doi.org/10.1016/j.jenvman.2012.08.021

32. Keen M, Brown VA, Dyball $R$ (2005) Social learning: a new approach to environmental management. In: Keen M, Brown VA, Dyball R (eds) Social learning in environmental management. Towards a sustainable future. Earthscan, London, pp 3-21
33. Flood RL, Romm NRA (1996) Contours of diversity management and triple loop learning. Kybernetes 7:154-163. https://doi.org/10.1108/ 03684929610149747

34. Diduck A, Bankes N, Clark D, Armitage D (2005) Upacking social learninig in social-ecological systems. In: Berkes F, Huebert R, Fast H et al (eds) Breaking Ice: Renewable Resource and Ocean Management in the Canadian North. Artic Institute of North America and University of Calgary Press, Calgary, pp 269-290

35. Argyris C, Schön D (1978) Organizational learning: a theory of action approach. Addision Wesley, Reading, MA

36. Villamayor-Tomas S (2017) The water-energy nexus in Europe and Spain: an institutional analysis from the perspective of the Spanish irrigation sector. In: Ziolkowska JR, Peterson JM (eds) Competition for Water Resources: Experiences and Management Approaches in the US and Europe. Elsevier Inc., Amsterdam, NL; Oxford, UK; Cambridge, USA, pp 105-122

37. Schlüter A, Theesfeld I (2010) The grammar of institutions: the challenge of distinguishing between strategies, norms, and rules. Ration Soc 22:445-475. https://doi.org/10.1177/1043463110377299

38. Ramaswami A, Weible C, Main D et al (2012) A social-ecologicalinfrastructural systems framework for interdisciplinary study of sustainable city systems: an integrative curriculum across seven major disciplines. J Ind Ecol 16:801-813. https://doi.org/10.1111/j.1530-9290. 2012.00566.x

39. Prior J (2016) The norms, rules and motivational values driving sustainable remediation of contaminated environments: a study of implementation. Sci Total Environ 544:824-836. https://doi.org/10.1016/j. scitotenv.2015.11.045

40. Schwartz SH (1992) Universals in the content and structure of values: theoretical advances and empirical tests in 20 countries. Adv Exp Soc Psychol 25:1-65. https://doi.org/10.1016/S0065-2601(08)60281-6

41. Schwartz SH, Bilsky W (1987) Toward a universal psychological structure of human values. J Pers Soc Psychol 53:550-562. https://doi.org/10.1037//00223514.53.3.550

42. Van de Poel I, Royakkers LMM (2011) Ethics, technology and engineering: an introduction. Wiley-Blackwell, Chichester, West Sussex

43. Aligica PD, Tarko V (2013) Co-production, polycentricity, and value heterogeneity: the Ostroms' public choice institutionalism revisited. Am Polit Sci Rev 107:726-741. https://doi.org/10.1017/S0003055413000427

44. Dietz T, Fitzgerald A, Shwom R (2005) Environmental values. Annu Rev Environ Resour 30:335-372. https://doi.org/10.1146/annurev.energy.30. 050504.144444

45. Pojman LP (1997) What is moral philosophy? In: Shrader-Frechette KS, Westra L (eds) Technology and Values. Rowman \& Littlefield Publishers, Lanham, Md, pp 11-23

46. Van de Poel I (2009) In: AWM M (ed) Values in engineering design. Handbook of the Philosophy of Science, pp 973-1006

47. Taebi B, Kadak AC (2010) Intergenerational considerations affecting the future of nuclear power: equity as a framework for assessing fuel cycles. Risk Anal 30:1341-1362. https://doi.org/10.1111/j.1539-6924.2010. 01434.x

48. Milchram C, van de Kaa G, Doorn N, Künneke R (2018) Moral Values as Factors for Social Acceptance of Smart Grid Technologies. Sustainability 10: 2703. https://doi.org/10.3390/su10082703

49. Verbeek PP (2008) Obstetric ultrasound and the technological mediation of morality: a postphenomenological analysis. Hum Stud 31:11-26. https://doi. org/10.1007/s10746-007-9079-0

50. Winner $L$ (1980) Do artifacts have politics? Daedalus 109:121-136

51. Joerges B (1999) Do politics have artefacts? Soc Stud Sci 29:411-431

52. Shilton K, Koepfler JA, Fleischmann KR (2013) Charting sociotechnical dimensions of values for design research. Inf Soc 29:259-271. https://doi. org/10.1080/01972243.2013.825357

53. Albrechtslund A (2007) Ethics and technology design. Ethics Inf Technol 9 63-72. https://doi.org/10.1007/s10676-006-9129-8

54. Inde D (1990) Technology and the lifeworld: from garden to earth. Indiana University Press

55. Kroes P, Verbeek PP (2014) Some misunderstandings about the moral significance of technology. In: Kroes P, Verbeek PP (eds) The Moral Status of Technical Artefacts. Springer, Dordrecht, pp 75-88

56. van de Poel I (2018) Design for value change. Ethics Inf Technol 0:1-5. https://doi.org/10.1007/s10676-018-9461-9 
57. Correljé A, Groenewegen J (2009) Public values in the energy sector: economic perspectives. Int J Public Pol:207-225

58. Knudsen C (1993) Modelling rationality, institutions and processes in economic theory. In: Mäki U, Gustafsson B, Knudsen C (eds) Rationality, institutions and economic methodology. Routledge, London, UK, pp 265-299

59. Williamson OE (1998) Transaction cost economics: how it works; where it is headed. Economist (Leiden) 146:23-58. https://doi.org/10.1023/a: 1003263908567

60. Rokeach M (1973) The nature of human values. Free Press, New York

61. Cheng AS, Fleischmann KR (2010) Developing a meta-inventory of human values. Proc ASIST Annu Meet 47. https://doi.org/10.1002/meet.14504701232

62. van der Werff E, Steg $L$ (2016) The psychology of participation and interest in smart energy systems: comparing the value-belief-norm theory and the value-identity-personal norm model. Energy Res Soc Sci 22:107-114. https:// doi.org/10.1016/j.erss.2016.08.022

63. Flanagan M, Howe DC, Nissenbaum H (2008) Embodying values in technology: theory and practice. In: Van Den Hoven J, Weckert J (eds) Information technology and moral philosophy. Cambridge University Press, New York, pp 322-353

64. Bush PD (2009) The neoinstitutionalist theory of value: remarks upon receipt of the Veblen-Commons Award. J Econ Issues 43:293-306. https://doi.org/ 10.2753/JEI0021-3624430202

65. Shrader-Frechette KS, Westra L (1997) In: Shrader-Frechette KS, Westra L (eds) Overview: ethical studies about technology. Technology and Values. Rowman \& Littlefield Publishers, Lanham, Md, pp 3-10

66. Devine-Wright P (2005) Beyond NIMBYism: towards an integrated framework for understanding public perceptions of wind energy. Wind Energy 8:125-139. https://doi.org/10.1002/we.124

67. Barry C (2001) The ethical assessment of technological change: an overview of the issues. J Hum Dev 2:167-189. https://doi.org/10.1080/ 14649880120067257

68. World Bank (2013) Toward a sustainable energy future for all. World Bank Group's Energy Sect http://documents.worldbank.org/curated/en/74560146 8160524040/pdf/795970SSTOSecMO0box377380BOOPUBLICO.pdf

69. Siciliano G, Urban F (2017) Equity-based natural resource allocation for infrastructure development: evidence from large hydropower dams in Africa and Asia. Ecol Econ 134:130-139. https://doi.org/10.1016/j.ecolecon.2016.12.034

70. McGinnis MD (2011) Networks of adjacent action situations in polycentric governance. Policy Stud J 39:51-78. https://doi.org/10.1111/j.1541-0072. 2010.00396.x

71. European Commission (2018) Energy strategy and energy union. http:// ec.europa.eu/energy/en/topics/energy-strategy-and-energy-union. Accessed 19 Jan 2018

72. Hodgson GM (2015) On defining institutions: rules versus equilibria. J Institutional Econ 11:497-505. https://doi.org/10.1017/S1744137415000028

73. Siebenhüner B, Rodela R, Ecker $F$ (2016) Social learning research in ecological economics: a survey. Environ Sci Policy 55:116-126. https://doi. org/10.1016/j.envsci.2015.09.010

74. Cole DH (2017) Laws, norms, and the institutional analysis and development framework. J Institutional Econ 13:829-847. https://doi.org/10.1017/ S1744137417000030

\section{Publisher's Note}

Springer Nature remains neutral with regard to jurisdictional claims in published maps and institutional affiliations.

Ready to submit your research? Choose BMC and benefit from:

- fast, convenient online submission

- thorough peer review by experienced researchers in your field

- rapid publication on acceptance

- support for research data, including large and complex data types

- gold Open Access which fosters wider collaboration and increased citations

- maximum visibility for your research: over $100 \mathrm{M}$ website views per year

At BMC, research is always in progress.

Learn more biomedcentral.com/submissions 